\title{
Deflating the Determination Argument
}

\author{
Jared Henderson \\ Forthcoming in Thought
}

\begin{abstract}
This paper argues for the compatibility of deflationism and truth-conditional semantic theories. I begin by focusing on an argument due to Dorit Bar-On, Claire Horisk, and William Lycan for incompatibility, arguing that their argument relies on an ambiguity between two senses of the expression 'is at least.' I go on to show how the disambiguated arguments have different consequences for the deflationist, and argue that no conclusions are established that the deflationist cannot accommodate. I then respond to some objections and gesture at a more general defense of the compatibility claim.
\end{abstract}

Deflationists about truth have often seen their position as incompatible with theories of meaning which explicate, explain, or analyze linguistic meaning in terms of truth, including theories which make important use of the notion of a truth-condition. Paul Horwich has claimed if one endorses a Davidsonian theory of meaning and his preferred brand of deflationism, minimalism, then one is "faced with something like a single equation with two unknowns" [10,68]. Philosophers opposed to deflationism, such as Davidson [6, 7] and Lynch [15], have also pressed the point that a truth-conditional theory of meaning is incompatible with deflationism, though their reasons have varied. ${ }^{1}$ This is a problem for deflationists: truth-conditional theories of meaning are widely accepted in semantics, and they seem like the best theories of meaning presently available. Even if deflationists will ultimately opt for non-truth-conditional theories of meaning, it is a serious mark against deflationary theories of truth if they cannot be made compatible with a theory of meaning enjoying so much success in semantics.

\footnotetext{
"This is the uncorrected version submitted to the journal. Please cite the published version in Thought.

${ }^{1}$ See Horisk $[8,9]$ and Kolbel [14] for discussions of the incompatibility claim.
} 
The source of the purported incompatibility comes from a common understanding of deflationism and a common assumption about truth-conditional theories of meaning. The common understanding of deflationism, the one I use throughout this paper, is that deflationism is a view about both the property or concept of truth and the truth predicate, where the property or concept is non-explanatory and the predicate is merely expressive. ${ }^{2}$ The common assumption about truth-conditional theories of meaning, which I argue against in this paper, is that truth-conditional theories of meaning require truth-conditions, and thus truth, to play a substantive explanatory role.

Assuming incompatibility, deflationists have pursued giving non-truth-conditional theories of meaning. Horwich $[11,12]$ provides an extended defense of a use theory of meaning and has argued that a truth-conditional theory of meaning cannot hope to provide a naturalistic reduction of meaning and thus semantics in its truth-conditional form is not a proper science. The relevant aspect of Horiwch's position is that it avoids making use of truth-conditions, thus making his theory impeccably deflationary. Deflationists do not need to explain away truth's role in a theory of meaning if they endorse a use theory, because truth plays no apparent role in the theory.

But there is a problem facing deflationists who think they can give a theory of meaning free from truth-conditions. Dorit Bar-On, Claire Horisk, and William Lycan $[1,2]$ have presented an argument to the effect that a theory of meaning must involve truth-conditions. Any theory of meaning which makes no mention of truth-conditions has thus ignored a necessary component of a theory of meaning. So in order to give a satisfactory theory of meaning, deflationists will need to find some way to accommodate truth-conditions into their theory. ${ }^{3}$ Here is the argument:

(i) A sentence's meaning taken together with a possible world determines the sentence's truth-value at that world.

(ii) $\therefore$ A sentence-meaning is at least a function from possible worlds to truthvalues.

\footnotetext{
${ }^{2}$ For similar formulations, see Beall $[3,276]$ and Waxman [17, 435], where truth is property or concept that does not explain anything in the world, the concept of truth is captured by the T-Schema or a related schema (or perhaps the rules governing the inferential behavior of the predicate), and 'is true' is a device of generalization, not a device for naming a property.

${ }^{3}$ In [1], Bar-On et al present their conclusion as a dilemma: either deflationism is compatible with truth-conditional theories of meaning or it is false. I make no explicit mention of this dilemma, though what I say could be rewritten as taking the first horn on the deflationist's behalf.
} 
(iii) Such a function is a truth-condition.

(iv) $\therefore$ A sentence-meaning is at least a truth-condition.

The upshot of this argument, according to Bar-On, Horisk, and Lycan (henceforth $B H L$ ), is that a truth-conditional theory of meaning requires truth-conditions (and thus truth) to play an explanatory role. If that is the case, then truth-conditional theories are incompatible with deflationism. But I argue in this note that their defense of this conclusion is unsuccessful: BHL give us no reason to think deflationism and truth-conditional semantic theories are incompatible, as they give us no reason to accept the claim that truth-conditions play an explanatory role.

The Determination Argument relies on an equivocation between two readings of the expression 'is at least.' Call these readings lightweight and heavyweight for ease of reference. In $\S 1$, I focus on the lightweight reading of the argument, where 'is at least' is read as a bare association of meaning and truth-conditions. I argue the lightweight reading of the argument is sound, but the conclusion poses no problem for the deflationist. In $\S 2$, I focus on the heavyweight reading, where 'is at least' is read as a claim about partial consitution. I argue the conclusion of the heavyweight reading of the argument would be a problem for the deflationist, but the argument is invalid. In $\S 3$, I respond to objections and gesture toward a more general defense of the compatibility of deflationary theories of truth and truth-conditional semantic theories.

\section{The lightweight reading}

I above noted an ambiguity in the locution 'is at least' in premises (ii) and (iv) of the Determination Argument. Premise (ii) is ambiguous between a restatement of premise (i) and of a substantive claim about what it is that explains a sentence's meaning. That is, the premise is ambiguous between a claim about some feature a meaning has (previously stated in (i)) and a claim about in virtue of what a sentence has the meaning that it does. This corresponds to two senses of the claim that meaning must involve truth-conditions.

Note that (i) is a claim about sufficiency. ${ }^{4}$ It is the claim that a sentence's meaning is sufficient for that sentence to have a particular truth-value at a particular world. (We will set aside the issue of whether or not (i) is true. Following BHL,

\footnotetext{
${ }^{4}$ BHL call (i) a sufficiency claim as well: "The trick of the Determination Argument is to move from the sufficiency claim to a functional characterization of meaning" [1, 14].
} 
I assume it is. ${ }^{5}$ ) We can think of a sentence's meaning, then, as a function from worlds to truth-values. We can think of a sentence's meaning in this way because that's all there is to something being a function. A function takes arguments and outputs values. In the case of sentence-meanings, the arguments are worlds and the values are truth-values. ${ }^{6}$

According to the lightweight reading of the argument, (ii) is a restatement of (i). We establish in premise (i) that sentence-meanings are functions of a certain kind, and from this we conclude they are functions of that kind. (iii) is a terminological stipulation, telling us to call any function from worlds to truth-values a truthcondition. So (iv) follows trivially. This reading of the argument is lightweight because it says nothing about the metaphysics or nature of meaning, nor the explanatory role of truth in a theory of meaning. So long as the deflationist accepts (i) and can explain the notion of a function from worlds to truth-values in a deflationarily acceptable way, the Determination Argument fails to establish much of substance about the involvement of truth-conditions in a theory of meaning.

The prospects for the deflationist look rather good. Taking Horwich [10] as the archetypal deflationist, we can say the deflationist holds that the concept of truth is captured by our general disposition to accept instances of the following schema:

T-Schema: The proposition that $p$ is true iff $p$

But the T-Schema is stated in terms of propositions, and so far we have talked about sentences and sentence-meanings. Further, we have so far not talked about truth, but the relation of truth at-we are concerned with whether a sentence is true at some possible world.

The deflationist should make use of a slightly different schema. Let ' $s$ ' be a sentence name, ' $p$ ' an interpreted sentence, '@' be the actual world and ' $w$ ' a variable ranging over worlds:

Sententential T-Schema: Given that $s$ means that $p$ at @, $s$ is true at $w$ iff $p$ at $w$ The deflationist makes use of the relations of truth at and meaning at in order to accommodate the fact that a sentence having a certain meaning suffices for

\footnotetext{
${ }^{5}$ It is open to the deflationist to deny (i), of course. But I set aside that possibility in order to grant as much as possible to BHL. Granting (i) and showing how the Determination Argument fails puts me in a stronger dialectical position.

${ }^{6}$ I speak of meanings being functions here, but I do not mean to suggest meanings are to be literally identified with functions-rather, meanings are the sorts of things we adequately model with functions, or meanings determine functions.
} 
its truth-value at a world. We want to know whether $s$ is true at some world or not. Hold fixed an interpretation of $s$ and then evaluate $s$ at that world given its intepretation at the actual world. Hold fix the interpretation that $s$ means that $p$-then to evaluate $s$ at $w$, we determine whether or not $p$ at $w$. If $p$ at $w$, then $s$ is true at $w$. If it is not the case that $p$ at $w$, then $s$ is not true at $w$.

Before moving on to the heavyweight reading, let's take stock. I noted that if we read (i) as a claim about sufficiency and (ii) as a restatement of (i), we have a clear sense in which a meaning is a function from worlds to truth-values, and so meaning must involve truth-conditions. But this sort of involvement is acceptable to the deflationist. The lightweight Determination Argument succeeds in establishing that a meaning must involve truth-conditions, but it does not succeed in posing a problem for the deflationist.

\section{The heavyweight reading}

Now we turn to the heavyweight reading. In this section, I will argue that the sort of involvement the heavyweight Determination Argument purports to establish is problematic for the deflationist. But luckily for the deflationist, the heavyweight Determination Argument is invalid.

On the heavyweight reading of the Determination Argument, the 'is at least' locution in (ii) is read as expressing a metaphysically explanatory relation between a sentence's meaning and its truth-condition. The preferred reading indicated by BHL is one of partial constitution $[1,16]$. I do not wish to argue at length for the claim that if truth-conditions do hold some metaphysically explanatory relationship to meanings, then deflationism is false, nor that partial constitution is one of these metaphysically explanatory relationship. Instead, I grant these assumption's on BHL's behalf. ${ }^{7}$ Without these assumptions, the Determination Argument fails to pose even a prima facie problem for the deflationist. The relevant question, then, is whether or not the heavyweight Determination Argument establishes the partial constitution claim.

The heavyweight Determination Argument moves from a claim about sufficiencypremise (i)-to a claim about constitution. That is, it moves from a sufficiency

\footnotetext{
${ }^{7}$ See Lynch [15] for a defense of the claim that deflationists are barred from using truth-conditions in a theory of meaning in some robust sense. And see Bennett [4] for an overview of what Bennett calls building relations-plausibly, partial constitution is one of these relations. And so to explain meanings by claiming that truth-conditions partially constitute them is to use truth-conditions in a robust explanation. Thus, incompatibility.
} 
claim about meaning to a claim about a "substantive explanatory role in the theory of meaning" $[1,14]$. BHL also talk in terms of what it is that makes a sentence have the meaning it has $[1,15]$, and they think that a partial answer to that question is the sentence's truth-condition.

For clarity, here is a restatement of the Determination Argument in terms of partial constitution, i.e. the heavyweight Determination Argument:

(v) A sentence's meaning taken together with a possible world determines the sentence's truth-value at that world.

(vi) $\therefore$ A sentence-meaning is partially constituted by a function from possible worlds to truth-values.

(vii) Such a function is a truth-condition.

(viii) $\therefore$ A sentence-meaning is partially constituted by a truth-condition.

Here is the major objection to the heavyweight Determination Argument. In general, showing that $x$ is sufficient for $y$ is not enough to conclude that $x$ is at least $y$, i.e. that $y$ partially constitutes $x$. The reason for this is simple enough: constitution and explanation facts are more fine-grained than modal facts. The distinction I am after is between sufficiency or sufficing for and explaining or constituting. It is a fact that a sentence's meaning is a function from worlds to truth-values in the following sense: when $s$ means that $p, s$ is true at $w$ iff $p$ at $w$. When "Snow is white" means that snow is white, "Snow is white" is true at $w$ if snow is white at $w$. So a sentence having a particular meaning suffices for it having a particular truth-condition. But under the heavyweight reading, the argument is taken to establish that truth-conditions explain meaning by way of constitution. Thus, the inference from (v) to (vi) is erroneous: we cannot rightly infer a claim about explanation from a modal claim.

To make this point clearer, we can consider two different positions which differ importantly in the order of explanation between meanings and truth-conditions, given in Figures $1 \& 2$.

In these figures, read the arrows as indicating the order of explanation in a theory of meaning. In Figure 1, we have the view advocated for by BHL: the view on which a sentence having its particular meaning is explained by having its particular truth-condition. In Figure 2, we have an alternative view, the view on which a sentence having its particular truth-condition is explained by having its 


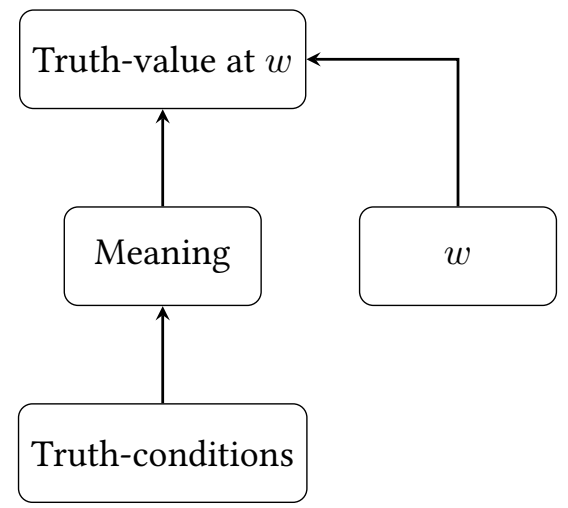

Figure 1

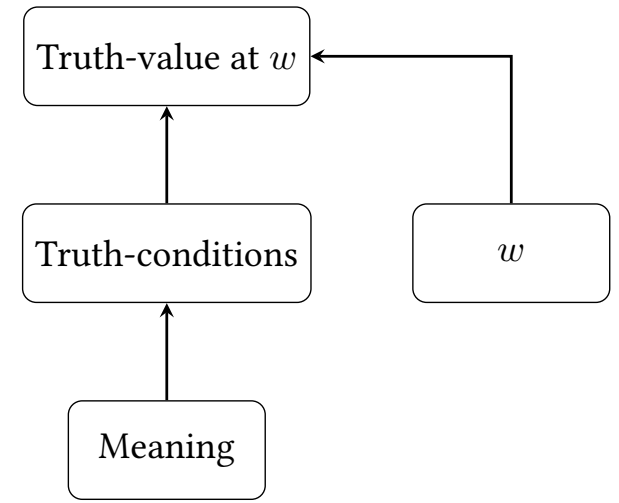

Figure 2

particular meaning. The view in Figure 2 is most at home with Russellian views of propositions. On these views, a proposition is a structured entity. ${ }^{8}$ For instance, the proposition that Desdemona loves Othello is something like the structured entity $\langle$ Desdemona, Loves, Othello $\rangle{ }^{9}$ Structured proposition views typically do not deny sentences have truth-conditions, but they also do not think it is because a sentence has a particular truth-condition that it has its particular meaning. Nor will they accept that a sentence's meaning is partially constituted by its truth-conditions-it is hard to see how a structure like 〈Desdemona, Loves, Othello〉 could be partially constituted by truth-conditions. So the Russellian ought to opt for the view in Figure 2 as opposed to BHL's preferred view in Figure 1.

Both Figures $1 \& 2$ are consistent with (v). So we can see that simply noting that a sentence's meaning taken together with a possible world determines its truth-value, i.e. premise (v) of the heavyweight Determination Argument, will not tell us which order of explanation is the correct one. The heavyweight reading of the Determination Argument is invalid.

We can press the point further. The above objection relies on the basic observation that order of explanation cannot be rightly inferred from modal facts alone. But we also cannot infer that there is any explanation, in either direction, from the modal facts alone. The deflationist might be best served by going this route and denying both Figure $1 \& 2$, as both of these views take on substantial metaphysical commitments about explanatory order-namely, both views are committed to there being some metaphysically interesting relationship between meanings

\footnotetext{
${ }^{8}$ See Russell [16], and see King [13] for a more recent defense of the view.

${ }^{9}$ On King's view, propositions are much more complex than this-they involve constituents such as instantiation, which we omit for our purposes.
} 
and truth-conditions, and these are the sorts of robust metaphysical relations deflationists typically try to avoid. But the deflationist can, and should, accept lightweight truth-conditions as outlined in $§ 1$. These lightweight truth-conditions are acceptable to the deflationist, and they require no substantial metaphysical commitments.

\section{How the deflationist should proceed}

Most of the above has been suggestive remarks about what the deflationist should say to avoid the conclusion of the heavyweight Determination Argument. BHL anticipate the deflationist's resistance, and they pose two major objections. In this section, I respond to these objections. Along the way, I will sketch what the deflationist should say about truth-conditions, meanings, and their relationship.

The first objection offered by BHL is that "a truth-condition theorist ... should accept the burden of showing truth-conditions to play an explanatory role in her account. After all, why would one hold a truth-conditional theory of meaning unless one thought that truth-conditions explain certain facts about meaning?" [1, 16]. Call this the theoretical utility objection. According to this objection, if truthconditions are part of our theory of meaning, then we ought to put them to some theoretical work. But a proponent of the lightweight Determination Argument (and the deflationist) will not want to do this. Truth-conditions become theoretical danglers: they are part of the theory, but they do not amount to much. Assigning truth-conditions an explanatory role in which they at least partially constitute meanings avoids this objection, but this is incompatible with deflationism.

The second objection offered by BHL is that without the notion of a truthcondition explaining meaning, it is a mystery why it is that "Snow is white" is true iff snow is white. BHL writes:

Now, to reject the claim that meaning is explained by truth-conditions is to deny that the sentence's condition of truth-i.e., snow's being white-is part of what gives "Snow is white" the 'right' meaning. But we may reasonably wonder how, if this is so, it is snow's whiteness rather than the conductivity of copper or the greenness of Brussels sprouts, that is relevant to the truth of "Snow is white." If truthconditions do not explain meaning, what makes one worldly condition rather than another relevant to the truth of a given sentence? [1, 16-17]

Call this the mystery objection. According to this objection, without positing that 
a sentence having its particular truth-condition is what makes it the case that it has its particular meaning, it is at best mysterious why it is that certain conditions of the world make the sentence true and not others.

\subsection{The theoretical utility objection}

According to the theoretical utility objection, deflationists who reject that truthconditions really are a part of meaning are guilty of theoretical extravagance, taking on theoretical resources for which they have no use. And as BHL ask: why hold a truth-conditional theory of meaning unless one thought that truth-conditions explain certain facts about meaning?

I have two replies to this objection. First, deflationists cannot be faulted for countenancing truth-conditions in their theory of meaning given the results of the lightweight Determination Argument. Second, because they are forced to accept truth-conditions in the lightweight sense, they can help themselves to typical truth-conditional explanations of semantic phenomena, with the caveat that they can all be paraphrased into a deflationary language absent of substantive truth-talk.

I have argued that the deflationist can and should accept the results of the lightweight Determination Argument, and so they should accept the view that meanings are at least associated with truth-conditions. But here 'truth-condition' is understood in the lightweight sense of $§ 1$. It is hard to see why it is that the deflationist must then use truth-conditions to explain various semantic facts about entailment, synonymy, and so on. This is because according to the deflationist, meanings are not truth-conditions, but a sentence having a particular meaning suffices for that sentence having its particular truth-condition. So whenever a deflationist assigns a meaning to a sentence in the theory of meaning, a truthcondition is thereby assigned. This is a consequence of the lightweight Determination Argument. We can answer BHL's rhetorical question: deflationists can have truth-conditions in their theory of meaning because they get (lightweight) truth-conditions for free-this is what the lightweight Determination Argument shows.

Once deflationists have accepted lightweight truth-conditions, they can make use of them in giving semantic explanations. Let's focus on the case of entailment for simplicity. We can say that a sentence $s$ entails another sentence $s^{\prime}$ just in case at all worlds where $s$ is true, $s^{\prime}$ is true. This is a standard definition of entailment. And the deflationist can say that this is a perfectly fine definition, because there is a suitably deflated sense of truth and of truth-conditions available, as seen in $§ 1$. 
To put the talk of entailment into Horwich-friendly terms we help ourselves to the Sentential T-Schema. Let $s$ mean that $p$ and $s^{\prime}$ mean that $p^{\prime}$. Then $s$ is true at $w$ iff $p$ at $w$, and $s^{\prime}$ is true at $w$ iff $p^{\prime}$ at $w$. So $s$ entails $s^{\prime}$ just when, for all $w$, if $p$ at $w$, $p^{\prime}$ at $w$. Deflationists thus explain the semantic facts truth-conditionally, but these truth-conditional explanations are explicitly a shorthand for explanations that make no use of truth. Like the truth predicate, talking in terms of truth-conditions is useful for stating generalizations and for other theoretical purposes, but nonessential in principle. So just like deflationists are not barred from all uses of 'is true', they are not barred from talking in terms of truth-conditions.

\subsection{The mystery objection}

The second objection is the mystery objection. According to BHL we are in need of some explanation as to why it is that "Snow is white" is true iff snow is white rather than iff grass is green. Or, more broadly put, why are some instances of these biconditionals true and some false? BHL take it to be the case that the only explanation of these facts are that truth-conditions partially constitute meanings. Without this partial constitution claim, these facts are bound to remain a mystery.

First, we should note that this line of thought threatens to overgenerate. Recall again the Russellian view of propositions. I noted in $\S 2$ that it is hard to see how a structure such as $\langle$ Desdemona, Loves, Othello $\rangle$ could be partially constituted by its truth-conditions. Yet this is a viable proposal in the literature on propositions. If the mystery objection has something to it, then the Russellian conception of propositions is barred from the start. This gives us prima facie reason to be suspicious of the mystery objection.

But we can challenge this a bit more directly. The deflationist has an explanation for why it is that "Snow is white" is true iff snow is white-namely, it is because "Snow is white" means that snow is white. Recall that on the deflationary conception of truth, there is nothing to the step from meaning to truth-conditionsthis is made explicit in the Sentential T-Schema. After noting this, the deflationist is in a position to characterize lightweight truth-conditions for a sentence.

BHL can press the point, claiming that this deflationary explanation is just a restatement of the mystery. In reponse, the deflationist should make a distinction between two sorts of questions. One question is a semantic question: under what conditions is the sentence $s$ true? The other is a metasemantic question: why is it that the conditions under which $s$ is true are the conditions under which $s$ is true? It is also instructive for the deflationist to distinguish between two ways of 
talking about a sentence: we can talk about a sentence as a merely syntactic string, contingently having certain meaning-theoretic properties, and a sentence taken together with its meaning, necessarily having those meaning-theoretic properties. Consider an analogous case of names. It is a contingent matter that 'Hesperus' (taken as merely a string of letters concatenated in a certain way) denotes Hesperus. In this sense, the fact that 'Hesperus' denotes Hesperus is non-trivial, and it can reasonably be expected to be explained in giving a philosophical theory of meaning. When we consider 'Hesperus' (taken as a string of letters concatenated in a certain way with its actual meaning-theoretic properties), it is trivial that 'Hesperus' denotes Hesperus.

My suggestion is that the deflationist should admit that the question 'Why does $s$ mean that $p$ ?' is non-trivial and offer some explanation for why it is that $s$ means that $p$ (by appealing to, e.g., psychological and sociological facts about the use of the syntactic string ' $s$ '). But once it has been explained why it is that $s$ means that $p$, the deflationist should hold that it is trivially true that $s$ is true iff $p$. Collins [5] calls the following principle the Truth-From-Meaning principle.

Truth-From-Meaning: If $s$ means that $p, s$ is true iff $p$

While I know of no explicit endorsements of the Truth-From-Meaning principle by deflationists, if I am right then nothing bars them from accepting the principle (indeed, it is strikingly similar to the Sentential T-Schema in §1). Further, accepting something like this principle might be the only option available to the deflationist, considering that they must reject the conclusion of the heavyweight Determination Argument. But in order to avoid the conclusion that truth is somehow being reduced to meaning facts, the deflationist should instead posit that the Truth-From-Meaning principle expresses some relationship between the concept of truth and the concept of meaning. But, as I will briefly argue, this does not compromise the deflationist position.

We might think that admitting a connection between the concept of truth and the concept of meaning involves enriching the ordinary deflationist account of truth. If it does, then this involves a serious compromise of the deflationary position: if the deflationist must invoke, for instance, a primitive conceptual link, then it is not the case that our dispositions to accept the T-Schema fully capture the concept of truth. So the deflationist will want to avoid positing this sort of link. The deflationist should instead admit that a theory of truth is always going to be parasitic on a theory of meaning, and that the Truth-From-Meaning 
principle merely illustrates this point. Deflationists already admit this implicitly when they restrict instances of the T-Schema to meaningful sentences in the target language: ' $p$ ' is a schematic letter standing in for only the meaningful sentences of the target language-if a nonsense sentence takes the place of the schematic letter, the T-Schema fails. So even the formulation of the T-Schema requires a prior theory of meaning. That the deflationist then accepts something like the Truth-From-Meaning principle is no surprise.

This line of response admits that there is something to the mystery objection. The mystery objection claims that the deflationist has not, and cannot, explain why it is that "Snow is white" is true iff snow is white. I claim that the deflationist can answer this question in a two-step manner: by first explaining why it is that "Snow is white" means that snow is white, and then by helping themselves to the Truth-From-Meaning principle. But the deflationist is barred from attempting to explain the phenomena any further-so the satisfactoriness of the deflationary position depends on the satisfactoriness of this two-step explanation.

\section{Conclusion}

We have focused on the consequences of the Determination Argument for the deflationist about truth. I argued that the Determination Argument does not lead to any intolerable conclusions for the deflationist-in particular, it does not establish the heavyweight claim that truth-conditions partially constitute meanings.

What I have said above does not establish that deflationism and theories which make use of truth-conditions to explain facts about meaning are compatible; it merely shows that one argument for incompatibility fails. But in §3 I show how deflationists can make sense of truth-conditions. If our best theory of meaning only uses truth-conditions in this lightweight way, then deflationism really is compatible with truth-conditional theories of meaning. ${ }^{10}$

\footnotetext{
${ }^{10}$ Thanks to Rasa Davidaviciute, David Liebesman, Michael Lynch, Robin Jenkins, Colin McCullough-Benner, Toby Napoletano, Andrew Parisi, Dave Ripley, Lionel Shapiro, Andrew Tedder, the audience at the 2017 Society for Exact Philosophy, and most of all Keith Simmons for the many helpful comments and discussions on this paper and related issues. I also thank two very helpful anonymous referees for Thought.
} 


\section{Bibliography}

[1] Dorit Bar-On, Claire Horisk, and William Lycan. Deflationism, meaning, and truth-conditions. Philosophical Studies, (101):1-28, 2000.

[2] Dorit Bar-On, Claire Horisk, and William Lycan. Post-script to "Deflationism, meaning, and truth-conditions”. In Jc Beall and Bradley Armour-Garb, editors, Deflationary Truth, pages 344-352. Open Court, 2004.

[3] Jc Beall. Non-detachable validity and deflationism. In Colin Caret and Ole Hjortland, editors, Foundations of Logical Consequence. Oxford University Press, New York, 2015.

[4] Karen Bennett. Construction area (no hard hat required). Philosophical Studies, 154(1):79-104, 2011.

[5] John Collins. Truth or meaning? A question of priority. Philosophy and Phenomenological Research, 65:497-536, 2002.

[6] Donald Davidson. Truth and meaning. Synthese, 17(3):304-323, 1967.

[7] Donald Davidson. The folly of trying to define truth. The fournal of Philosophy, 93(6):263-278, 1996.

[8] Claire Horisk. The expressive role of truth in truth-conditional semantics. The Philosophical Quarterly, 57(229):535-557, 2007.

[9] Claire Horisk. Truth, meaning, and circularity. Philosophical Studies, (137): 269-300, 2008.

[10] Paul Horwich. Truth. Oxford University Press, New York, 1990.

[11] Paul Horwich. Meaning. Oxford University Press, New York, 1998.

[12] Paul Horwich. What's truth got to do with it? Linguistics and Philosophy, 31 (3):309-322, 2008.

[13] Jeffrey C. King. The Nature and Structure of Content. Oxford University Press, New York, 2007.

[14] Max Kölbel. Two dogmas of Davidsonian semantics. The fournal of Philosophy, 98(12):613-635, 2001. 
[15] Michael P. Lynch. Truth as One and Many. Oxford University Press, New York, 2009.

[16] Bertrand Russell. The Problems of Philosophy. Williams and Norgate, London, 1912.

[17] Daniel Waxman. Deflationism, arithmetic, and the argument from conservativeness. Mind, 126(502):429-463, 2017. 